\title{
Video comunitario colombiano en YouTube. Tipos de contenido y duración
}

\author{
Gloria Esperanza Navarro Sánchez*
}

DOI: https://doi.org/10.33571/revistaluciernaga.v12n23a5

\section{Resumen}

El artículo publica los resultados de la investigación que permitió establecer las características de 513 videos publicados en diez canales de YouTube creados por grupos colombianos dedicados a la producción de audiovisual comunitario o participativo, y clasificarlos según su contenido audiovisual y su duración. Se utilizó la metodología mixta y la técnica de recolección de la información fue el análisis de contenido y de datos descriptivos. Los canales objeto de estudio fueron: Kucha Suto Colectivo, Fundación Cine a la Calle, Red Comunicaciones Wayuu, ciudadcomuna, indigenasantioquia, SabaloIN, Fundación Cultural Ojo de Agua, de Fundescodes, Consejo Regional Indígena del HuilaCrihu, y ADCampesino.

Los hallazgos muestran que en estos canales se publican videos de una gran variedad de categorías entre las que se destacan los documentales, los publicitarios así como los minimetrajes y cortometrajes. Entre usuarios o emirecs se advierte la tendencia a publicar y ver videos breves.

Palabras clave: YouTube; comunicación comunitaria; comunicación participativa; audiovisual comunitario; autocomunicación; emirecs.

Recibido. Marzo 26, 2020

Aceptado. Abril 07, 2020 


\title{
Colombian community video on YouTube. Types of content and duration
}

\author{
Gloria Esperanza Navarro Sánchez*
}

DOI: https://doi.org/10.33571/revistaluciernaga.v12n23a5

\begin{abstract}
The article presents the results of the research that allowed to establish the characteristics of 513 videos posted on 10 YouTube channels developed by Colombian groups devoted to community or participatory audiovisual production, and to classify them according to their audiovisual content and duration. The mixed methodology was used and the technique for collecting the information was the analysis of content and descriptive data. The channels studied were: Kucha Suto Colectivo, Fundación Cine a la Calle, Red Comunicaciones Wayuu, ciudadcomuna, indigenasantioquia, SabaloIN, Fundación Cultural Ojo de Agua, de Fundescodes, Consejo Regional Indígena del HuilaCrihu, and ADCampesino.

The findings show that these channels post videos from a wide variety of categories, including documentaries, commercials, and mini-films and short films. Among users or broadcasters, there is a tendency to upload and watch short videos.
\end{abstract}

Keywords: YouTube; participatory communication; community communication; community audiovisual, self-communication; emirecs.

Received. March 26, 2020

Accepted. April 07, 2020

*Master's Degree in Digital Communication from the Universidad Pontificia Bolivariana Candidate for the title of Doctor in Human and Social Sciences at the National University of Colombia in Medellin. Orcid: https://orcid.org/0000-0003-3616-4894 ; e-mail: genavarros@unal.edu.co 


\title{
Vídeo da comunidade colombiana no YouTube. Tipos de conteúdo e duração
}

\author{
Gloria Esperanza Navarro Sanchez*
}

DOI: https://doi.org/10.33571/revistaluciernaga.v12n23a5

\section{Resumo}

O artigo publica os resultados da pesquisa que permitiu estabelecer as características de 513 vídeos publicados em dez canais do YouTube criados por grupos colombianos dedicados à produção audiovisual comunitária ou participativa, e classificá-los de acordo com o seu conteúdo audiovisual e duração. A metodologia mista foi utilizada e a técnica utilizada para recolher a informação foi a análise do conteúdo e os dados descritivos. Os canais estudados foram: Kucha Suto Colectivo, Fundación Cine a la Calle, Red Comunicaciones Wayuu, ciudadcomuna, indigenasantioquia, SabaloIN, Fundación Cultural Ojo de Agua, de Fundescodes, Consejo Regional Indígena del HuilaCrihu, e ADCampesino.

Os resultados mostram que estes canais publicam vídeos de uma grande variedade de categorias, incluindo documentários, comerciais, assim como mini-filmes e curtas-metragens. Entre os utilizadores ou emissoras, há uma tendência para publicar e ver vídeos curtos.

Palavras chave: YouTube; comunicação participativa; comunicação comunitária; audiovisual comunitário; auto-comunicação; emirecs.

Received. Março 26, $2020 \quad$ Accepted Abril 07, 2020 


\section{Infográfico}

\section{Video comunitario colombiano en YouTube. Tipos de contenido y duración.}

Gloria Esperanza Navarro Sánchez

https://doi.org/:10.33571/revistaluciernaga.v12n23a5
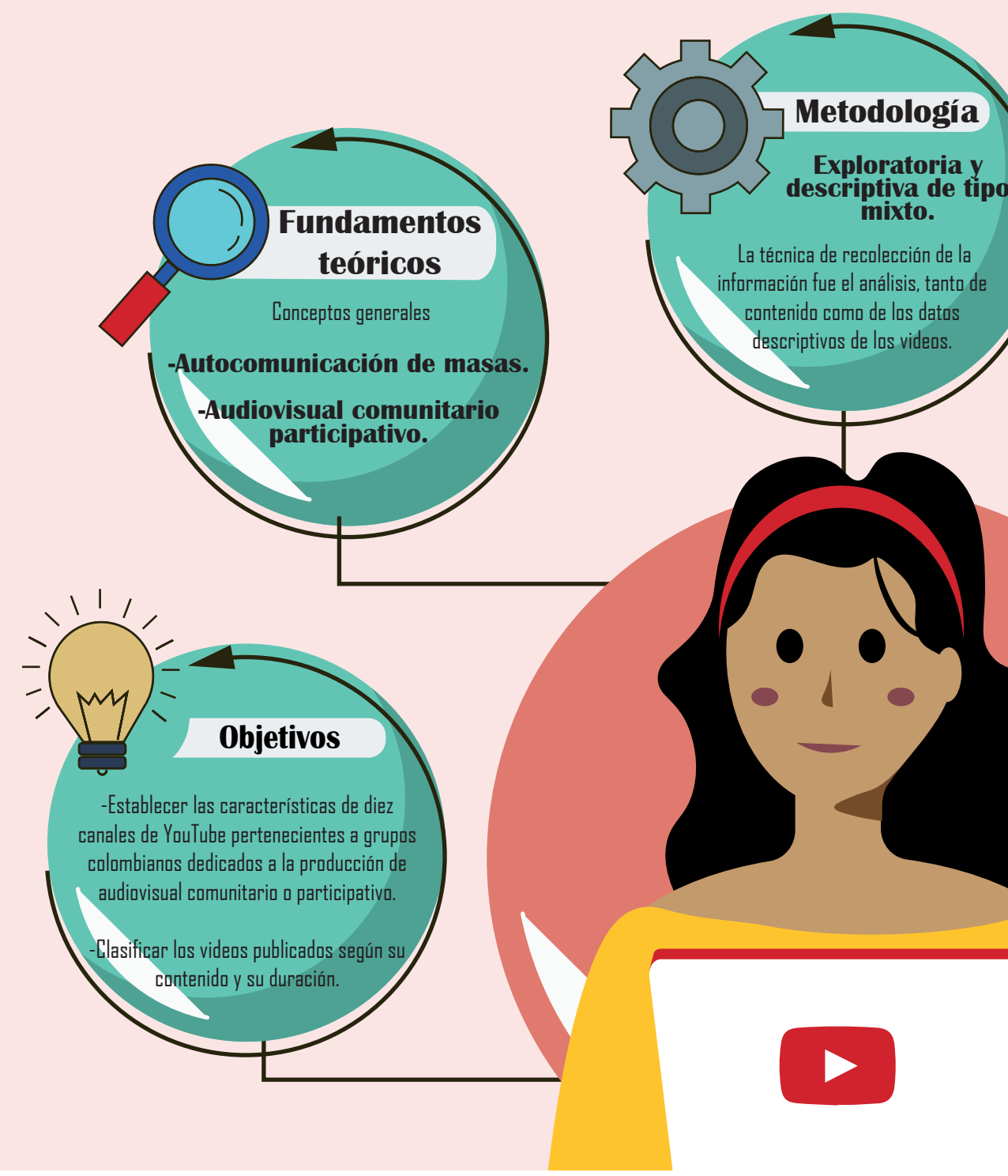

La técnica de recolección de la

información fue el análisis, tanta de

contenida cama de los datas

descriptivas de los videas.
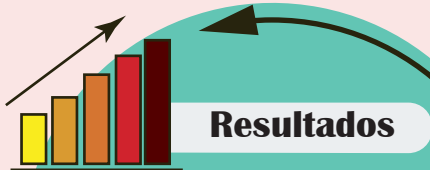

-El canal con más documentales publicadas fue Ciudadcomuna.

-Autocomunicación de masas.

-Audiovisual comunitario participativo.

$-$

-Establecer las características de diez canales de YouTube pertenecientes a grupos colambianos dedicados a la producción de audiovisual comunitario o participativo.

- Clasificar las videas publicados según su contenida y su duración. 


\section{Introducción}

Uno de los objetivos específicos de la investigación [1] fue establecer las características de diez canales de YouTube creados por grupos urbanos, rurales y étnicos de Colombia, dedicados a la producción audiovisual comunitaria o participativa, ubicados en diferentes lugares del país, desde el extremo norte hasta el suroccidente, y de los videos publicados en cada uno de ellos.

En este artículo se amplían los resultados obtenidos del análisis de los videos alojados en dichos canales, desde la fecha de su publicación hasta el 31 de diciembre de 2018. Las preguntas que guiaron el estudio fueron: ¿cuáles tipos de videos, según su contenido audiovisual, se publican en estos diez canales?, ¿cuáles tipos de videos se publican en mayor cantidad y en un mayor número de canales?, ¿cuáles tipos de videos según su duración se publican en estos diez canales y cuáles son más vistos por los usuarios?. El estudio permitió ampliar el conocimiento de los diferentes usos que los grupos dan a sus canales en YouTube, y las preferencias en cuanto al tiempo de duración de las producciones, tanto de quienes las publican como de quienes las visualizan.

\section{Fundamentos teóricos}

Los conceptos centrales de esta parte del estudio fueron el de autocomunicación de masas y el de audiovisual comunitario o participativo.

Aunque los medios masivos de comunicación como la prensa escrita, la radio o la televisión dominaron en el manejo de la información durante el siglo XX, con el auge de internet, sobre todo con la llegada de su versión 2.0, llamada también internet social o interactiva, en la primera década del siglo XXI, la estructura de funcionamiento de los medios de comunicación se fue transformando de jerárquica, estable y vertical a una más democrática, dinámica y reticular, en el que el poder de emitir información dejó de ser privilegio de unos pocos, y en la que cualquier persona con acceso a internet puede llegar a tener un medio de comunicación audiovisual, por ejemplo, un canal de televisión en YouTube, la plataforma digital de publicación de videos creada en 2005; esto es lo que Castells (2008, p. 8) denominó la autocomunicación de masas:

"un nuevo ámbito de comunicación y, en última instancia, (...) un nuevo medio, cuyo eje principal está compuesto por redes informáticas, cuyo lenguaje es digital y cuyos remitentes están distribuidos por todo el mundo y son globalmente interactivos".

Ello no implica la desaparición de otros medios como los interpersonales o los de masas, por el contrario "coexisten, interactúan y, más que sustituirse, se complementan entre sí" (Castells, 2009, p. 88), y los medios que van surgiendo pueden contener a todos los que le precedieron, tal como lo afirmó McLuhan (1996), esto sucede en YouTube, donde se pueden ver contenidos publicados por canales de televisión abierta y de suscripción tales como Caracol Televisión o History Channel, o de emisoras de radio como $\mathrm{RCN}$, que tienen sus propios canales en esta plataforma.

En esta época de medios participativos, ya no se habla de emisores o receptores, sino de usuarios, porque el receptor dejó de ser alguien que se limitaba a recibir mensajes, ahora puede ser también un participante activo del proceso de comunicación que también puede emitirlos, dentro un renovado y reforzado esquema comunicativo dialógico que puede funcionar de forma bidireccional, multidireccional o reticular.

El canadiense Jean Cloutier $(1973,2001)$ llama emirecs a estos usuarios, híbridos entre emisores y receptores que encuentran en las diferentes herramientas digitales disponibles en internet - redes sociales, plataformas de publicación de videos, blogs, entre otras - la facilidad para comunicar, ya no importa si no es un profesional que trabaja para un medio masivo, toda persona puede ejercer como 
nunca antes el derecho humano a la libertad de expresión, el cual "incluye el de no ser molestado a causa de sus opiniones, el de investigar y recibir informaciones y opiniones, y el de difundirlas, sin limitación de fronteras, por cualquier medio de expresión" (ONU,1948).

El audiovisual comunitario o participativo, es definido por Gumucio (2014, p. 23) "como aquel que involucra y promueve la apropiación de los procesos de producción y difusión por parte de la comunidad". Entre las finalidades de este tipo producciones es exhibirse ante los mismos grupos sociales donde se producen y presentarse en circuitos alternativos como los festivales de cine comunitario, algunos de los cuales cuentan en la actualidad con el apoyo de entes gubernamentales, como sucede en Colombia con el Ministerio de Cultura o las secretarías de cultura locales.

\section{Estado del arte}

Entre los estudios sobre audiovisual comunitario o participativo realizados en Colombia se encuentran los de Román (2009), Aguilera y Polanco (2011), Iriarte y Miranda (2011), Mazo (2012), Rodríguez (2013), Urrea (2013), Garcés (2015) y Lopera (2019). Es de destacar los de César Mazo (2012) y Frank Rodríguez (2013), ambos trabajos de grado de la Maestría en Comunicación Digital de la Universidad Pontificia Bolivariana (UPB) de Medellín, por su cercanía con el tema tratado en esta investigación. El primero de ellos, titulado Posibilidades del audiovisual comunitario en la cibercultura, analizó "las posibilidades que tiene el audiovisual comunitario para fortalecerse como proceso y producto al incorporar Internet como plataforma colaborativa y de publicación" (Mazo, 2012, p. 10), para lo cual utilizó la entrevista como técnica principal de recolección de información.

El estudio se enfocó en tres colectivos de video comunitario de la ciudad de Medellín (Full Producciones, Cinética 8 y Platohedro) que utilizan internet para publicar sus contenidos y que tienen en común estar liderados e integrados por jóvenes. Entre las conclusiones, se resalta el hecho de que los integrantes de estos colectivos utilizan internet y las tecnologías digitales sin obsesionarse con estas herramientas, sino de acuerdo a "sus necesidades, (...) porque tienen claro que no basta con tener las aplicaciones tecnológicas y la conectividad. En cambio, defienden la idea de que la clave está en la creación, la orientación de sus contenidos y las dinámicas participativas" (Mazo, 2012, p. 99). Por su parte, la investigación de Rodríguez (2013) Apropiación social de las tecnologías de la información y la comunicación (TIC) en las prácticas de los colectivos de video comunitario en Colombia, tuvo por objetivo principal diagnosticar los niveles de apropiación social de las TIC de tres experiencias de video comunitario realizado por la misma cantidad de colectivos colombianos en el que se identificaran aplicaciones, procesos y niveles de manejo de herramientas virtuales a fin de fortalecer y consolidar ese movimiento (P.12).

Esta investigación se centró en tres colectivos de video comunitario ubicados en diferentes regiones del país (Escuela Audiovisual Infantil de Belén de los Andaquíes, Caquetá; Tikal producciones, de Cali; y Sueños Films, de Bogotá) es de tipo cualitativo exploratorio y las técnicas de recolección de datos empleadas fueron la entrevista a profundidad, y la observación tanto participante como no participante en ambientes reales y virtuales.

Entre las conclusiones a las que llegó el autor se destacan que el uso de internet, sobre todo de redes sociales como Facebook o YouTube les ha permitido a estos colectivos de video comunitario "establecer relaciones con experiencias similares forjando redes de aprendizaje, información y comunicación" (Rodríguez, 2013, p. 80); los tres colectivos estudiados pueden clasificarse como prosumidores, ya que son a la vez productores y consumidores de contenidos; estos grupos acondicionan sus productos audiovisuales a las particularidades de internet: en su mayoría son de duración corta, se acompañan de materiales multimedia (fotos, ilustraciones y textos) y son 
distribuidos por las redes sociales haciendo uso de sus particularidades expresivas; y, por último, estos grupos se identifican como instancias de poder por el hecho de generar contenidos, lo que les da un valor de tipo político porque estas prácticas se constituyen en ejercicio de construcción ciudadana que evidencia la "apropiación colectiva de tecnologías y narrativas que invita a los participantes a ser solidarios y reconocer al otro en contextos de violencia en donde desarrollan su trabajo" (Rodríguez, 2013, p. 81).

En el contexto latinoamericano se destacan los estudios sobre audiovisual comunitario o participativo realizados por Zamorano (2009), Álvarez (2013), Torres (2013), Quintar, González y Álvarez (2014), Gumucio (2014), Aizpuru (2015), Cuevas (2016), Soler (2017), Molfetta (2017), Amador (2017), y Gonzales (2017), desde diferentes disciplinas de las ciencias humanas y sociales entre las que están la antropología, la comunicación social, la comunicación audiovisual, la pedagogía y el arte. En estas investigaciones predomina el enfoque cualitativo, la descripción, análisis y reflexión a partir de experiencias y procesos de realización de audiovisual comunitario o participativo, que incluyen a su vez procesos de transformación de los grupos sociales involucrados, entre los que se encuentran comunidades urbanas, rurales e indígenas, y personas con algún tipo de discapacidad física.

\section{Metodología}

La metodología empleada en esta parte de la investigación, perteneciente a la primera categoría de análisis, denominada características de los diez canales de YouTube, fue exploratoria y descriptiva de tipo mixto. Se eligió esta metodología porque facilita "la integración sistemática de los métodos cuantitativo y cualitativo en un sólo estudio" (Chen, 2006, citado por Hernández, Fernández y Baptista, 2014, p. 534) y es flexible al permitir a los investigadores crear diseños específicos de acuerdo con sus requerimientos particulares. La técnica de recolección de la información fue el análisis, tanto de contenido como de los datos descriptivos de los videos, estos últimos son llamados por otros investigadores datos de identificación (Villalobos, 2016, p. 50), características descriptivas (Zabala, 2018, p. 42), o datos de los videos (Fernández, 2015, p. 53).

La información se registró en matrices elaboradas con el programa Microsoft Excel, en las que se incluyeron datos de cada uno de los videos publicados en cada canal desde la fecha de su creación hasta diciembre de 2018. Se eligió este programa porque permite registrar información numérica y textual, consultarla fácilmente, utilizar fórmulas matemáticas, además de facilitar su almacenamiento: sólo fue necesario un archivo para guardar toda la información recolectada, dentro de este se abrieron diez hojas, en las que se crearon las matrices, una para cada canal. Para esta investigación la elección resultó ser funcional tanto para la recolección como para el análisis de la información y más práctico que usar las llamadas fichas de observación o fichas de análisis que se utilizan tradicionalmente como instrumento de recolección de datos y se diligencian de forma individual. El orden de registro en cada matriz fue de la fecha de publicación más antigua a la más reciente, gracias a que YouTube permite a los usuarios elegir el orden en que prefieren que aparezcan los videos publicados en cada canal.

En estas matrices se registraron los datos descriptivos de cada video (cualitativos y cuantitativos) tales como el título, el año de publicación, la cantidad de visualizaciones de cada uno, la dirección URL, su duración (en minutos y segundos, u horas, minutos y segundos) y categoría según esta. Para poder categorizar los videos según la duración se adaptaron (con algunas modificaciones) las propuestas de clasificación del Ministerio de Cultura de Colombia (2015, 2017) y el investigador español Demetrio Brisset (2015), las cuales se sintetizan en la Tabla 1. 
Tabla 1.

Categorías de producciones audiovisuales según su duración para este estudio

\begin{tabular}{|l|l|}
\hline \multicolumn{1}{|c|}{ Categorías } & \multicolumn{1}{c|}{ Duración } \\
\hline Micrometraje & Entre uno y diez segundos (1 s $-10 \mathrm{~s})$. \\
\hline Minimetraje & $\begin{array}{l}\text { Entre 11 segundos y seis minutos y 59 segundos (11 s }-6 \text { min } \\
\text { y } 59 \mathrm{~s}) .\end{array}$ \\
\hline Cortometraje & $\begin{array}{l}\text { Entre siete minutos, y 51 minutos y } 59 \text { segundos (7 min }-51 \\
\text { min y 59 s). }\end{array}$ \\
\hline Largometraje & Desde 52 minutos en adelante (=52 min $-+52 \mathrm{~min})$. \\
\hline
\end{tabular}

Fuentes: Ministerio de Cultura (2015, 2017) y Brisset (2015). Elaboración: Autora (2020).

Luego de realizar el registro de los datos descriptivos de cada canal se iniciaba el de los datos correspondientes al análisis de contenido; dentro de las mismas matrices (se utilizaron dos columnas, una para escribir la posible categoría y otra para escribir observaciones). En este caso de tipo nominal (Andréu, 2001) porque tenía como finalidad registrar información para clasificar los videos según su contenido audiovisual. Es necesario aclarar que las únicas dos categorías que se establecieron de forma previa fueron las de documentales y videos de ficción, debido a la exploración que realizó la autora para seleccionar los canales que harían parte del estudio, pero que no se establecieron otras categorías de contenidos específicas en las cuales ir ubicando los videos, debido a la gran variedad de tipos de contenido audiovisual que existen en la actualidad (a causa de los diversos usos por parte de los usuarios o emirecs de las plataformas digitales como YouTube) que hacen que las clasificaciones tradicionales de géneros audiovisuales resulten insuficientes. El proceso de categorización realizado, que inició en la fase de recolección de la información y finalizó en la fase de análisis de los datos recolectados, se explica de forma breve en la Tabla 2.

Tabla 2.

Proceso de categorización de videos según su contenido audiovisual

\begin{tabular}{|l|l|}
\hline \multicolumn{1}{|c|}{ Etapa } & \multicolumn{1}{|c|}{ Actividades realizadas y ejemplos } \\
\hline $\begin{array}{l}\text { 1. Observación } \\
\text { de los videos y } \\
\text { toma de notas. }\end{array}$ & $\begin{array}{l}\text { Luego de observar cada video se tomaba alguna nota } \\
\text { que ayudara a clasificarlo, por ejemplo: "es un reportaje", } \\
\text { "documental", o "ver de nuevo para poder clasificar". }\end{array}$ \\
\hline $\begin{array}{l}\text { 2. Unificación de } \\
\text { términos. }\end{array}$ & $\begin{array}{l}\text { Si en el proceso de recolección de información se registraron } \\
\text { términos diferentes para referirse a un mismo tipo de video, por } \\
\text { ejemplo: "anuncio", "aviso" o "publicidad", estos se unificaron en } \\
\text { el proceso de análisis de la información con el término "avisos } \\
\text { publicitarios". }\end{array}$ \\
\hline $\begin{array}{l}\text { 3. Agrupación de } \\
\text { videos similares. }\end{array}$ & $\begin{array}{l}\text { Los videos con características similares se fueron ubicando en } \\
\text { grupos, por ejemplo, los registrados como "noticiero", "reportaje", } \\
\text { "nota periodística" o "magacín televisivo", se ubicaron en el } \\
\text { grupo "informativos"; y los registrados como "saludo", "tarjeta } \\
\text { en video", "mensaje", "felicitación", o "reclamo", se agruparon } \\
\text { como "mensajes". }\end{array}$ \\
\hline
\end{tabular}




\begin{tabular}{|l|l|}
\hline $\begin{array}{l}\text { Establecimiento } \\
\text { de las } \\
\text { categorías. }\end{array}$ & $\begin{array}{l}\text { Esto se hizo con la búsqueda de bibliografía (sobre todo en libros y } \\
\text { artículos académicos) que sustentara la elección de los nombres de } \\
\text { las categorías que se iban creando y que ayudara a resolver dudas } \\
\text { que surgieron sobre la ubicación de algunos videos en determinadas } \\
\text { categorías, por ejemplo, en el caso de los tráileres o avances, se } \\
\text { tenía la duda de si eran resúmenes o videos publicitarios, pero la } \\
\text { explicación encontrada en un artículo académico permitió ubicarlos } \\
\text { como publicitarios. }\end{array}$ \\
\hline $\begin{array}{l}\text { 5. Cuantificación } \\
\text { de las } \\
\text { categorías. }\end{array}$ & $\begin{array}{l}\text { Se establecieron las cantidades y porcentajes de videos de cada } \\
\text { categoría en cada canal y luego se unificó la información. }\end{array}$ \\
\hline
\end{tabular}

Elaboración propia.

La información se recolectó entre los meses de febrero y junio de 2018, fue necesario hacer revisiones de los canales de forma mensual, con el fin detectar y registrar los nuevos videos que se publicaran en cada uno, y los cambios en datos como la cantidad de visualizaciones de cada video. La última revisión se realizó el 31 de diciembre de 2018.

\subsection{Muestra}

La muestra fue de tipo no probabilístico o propositivo (Hernández et al., 2010, p. 580) y de ella hicieron parte diez canales de YouTube creados y utilizados por la misma cantidad de grupos dedicados a la producción de audiovisual comunitaria o participativa ubicados en diferentes regiones de Colombia (Caribe, Andina y Pacífica), tratando de que resultara heterogénea respecto a la ubicación geográfica y a los contextos sociales y culturales, que tuvieran documentales entre sus publicaciones por ser estos parte fundamental de la investigación; sin tener en cuenta la cantidad que se hubiera publicado en cada canal; se consideró también que se ubicaran en alguno de los tres tipos de grupos dedicados a la producción audiovisual comunitaria establecidos: urbanos, rurales y étnicos, con base en los tipos propuestos por Gumucio (2014).

Los grupos de producción audiovisual comunitaria o participativa, objeto del estudio, fueron localizados por medio de una observación exploratoria (Arjona, 2012, p. 5) utilizando tanto motores de búsqueda de internet como Google y Google Académico, y el de YouTube. También utilizando términos de búsqueda como "grupos de video comunitario en Colombia" "video comunitario colombiano", "video participativo colombiano", "audiovisual comunitario en Colombia", "audiovisual participativo en Colombia", entre muchos otros; y se seleccionaron luego de comprobar que tenían un canal en la plataforma YouTube con videos publicados y luego de descartar de la muestra algunos canales que aparecían registrados a nombre de un solo integrante, con la idea de que los elegidos mantuvieran la esencia comunitaria o participativa de los grupos a los que pertenecen y no se tratara de iniciativas personales. También se descartaron canales con menos de diez videos publicados por considerar que no darían aportes significativos. Este proceso de selección se llevó a cabo a lo largo del año 2017. Los diez canales que conformaron la muestra se encuentran en la Tabla 3. 
Tabla 3.

Grupos de audiovisual comunitario o participativo que conformaron la muestra

\begin{tabular}{|c|c|c|c|c|}
\hline Canal de YouTube & $\begin{array}{l}\text { Fecha de } \\
\text { creación del } \\
\text { canal }\end{array}$ & $\begin{array}{c}\text { Grupo de } \\
\text { audiovisual } \\
\text { comunitario o } \\
\text { participativo al que } \\
\text { pertenece el canal }\end{array}$ & $\begin{array}{c}\text { Ubicación } \\
\text { geográfica } \\
\text { del grupo de } \\
\text { audiovisual } \\
\text { comunitario o } \\
\text { participativo. }\end{array}$ & $\begin{array}{l}\text { Tipo de grupo, } \\
\text { adaptación de } \\
\text { clasificación de } \\
\text { Gumucio (2014). }\end{array}$ \\
\hline $\begin{array}{l}\text { 1. Kucha Suto Colectivo } \\
\text { [2] }\end{array}$ & $\begin{array}{c}7 \text { de } \\
\text { mayo } \\
\text { de } 2012 .\end{array}$ & $\begin{array}{c}\text { Colectivo de } \\
\text { Comunicaciones } \\
\text { Kuchá-Suto de } \\
\text { Palenque. }\end{array}$ & $\begin{array}{l}\text { Corregimiento de } \\
\text { San Basilio de } \\
\text { Palenque, municipio } \\
\text { de Mahates, Bolívar. } \\
\text { Región Caribe. }\end{array}$ & $\begin{array}{c}\text { Étnico } \\
\text { (afrocolombiano). }\end{array}$ \\
\hline $\begin{array}{l}\text { 2. Fundación Cine a la } \\
\text { Calle }\end{array}$ & $\begin{array}{c}30 \text { de marzo } \\
\text { de } 2017 .\end{array}$ & $\begin{array}{l}\text { Fundación Cine a la } \\
\text { Calle. }\end{array}$ & $\begin{array}{c}\text { Barranquilla, } \\
\text { Atlántico. Región } \\
\text { Caribe. }\end{array}$ & Urbano. \\
\hline $\begin{array}{l}\text { 3. Red Comunicaciones } \\
\text { Wayuu }\end{array}$ & $\begin{array}{l}25 \text { de marzo } \\
\text { de } 2015 .\end{array}$ & $\begin{array}{c}\text { Red de } \\
\text { Comunicaciones } \\
\text { del Pueblo Wayuu - } \\
\text { Pütchiimaajana. }\end{array}$ & $\begin{array}{c}\text { Territorio wayuu. La } \\
\text { Guajira (Colombia) y } \\
\text { El Zulia (Venezuela) } \\
\text { Región Caribe. }\end{array}$ & Étnico (indígena). \\
\hline 4.Cciudadcomuna & $\begin{array}{c}22 \text { de } \\
\text { noviembre } \\
\text { de } 2011 .\end{array}$ & $\begin{array}{l}\text { Corporación para } \\
\text { la Comunicación } \\
\text { Ciudad Comuna. }\end{array}$ & $\begin{array}{l}\text { Medellín, Antioquia. } \\
\text { Región Andina. }\end{array}$ & Urbano. \\
\hline 5. Indigenasantioquia & $\begin{array}{c}19 \text { de } \\
\text { noviembre } \\
\text { de } 2012 .\end{array}$ & $\begin{array}{l}\text { Organización } \\
\text { Indígena de } \\
\text { Antioquia, OIA. }\end{array}$ & $\begin{array}{l}\text { Medellín, Antioquia. } \\
\text { Región Andina. }\end{array}$ & Étnico (indígena). \\
\hline 6. SabaloIN & $\begin{array}{l}19 \text { de junio } \\
\text { de } 2012 \text {. }\end{array}$ & Sábalo Producciones. & $\begin{array}{c}\text { Manizales, Caldas. } \\
\text { Región Andina. }\end{array}$ & Urbano \\
\hline $\begin{array}{l}\text { 7. Fundación Cultural } \\
\text { Ojo de Agua }\end{array}$ & $\begin{array}{l}12 \text { de } \\
\text { octubre de } \\
2011 .\end{array}$ & $\begin{array}{c}\text { Fundación Cultural } \\
\text { Ojo de Agua. }\end{array}$ & $\begin{array}{l}\text { Villa de Leyva, } \\
\text { Boyacá. Región } \\
\text { Andina. }\end{array}$ & Rural. \\
\hline 8. de Fundescodes [3] & $\begin{array}{l}21 \text { de marzo } \\
\text { de } 2013 .\end{array}$ & $\begin{array}{c}\text { Fundación Espacios } \\
\text { de Convivencia y } \\
\text { Desarrollo Social, } \\
\text { Fundescodes. }\end{array}$ & $\begin{array}{c}\text { Buenaventura, Valle } \\
\text { del Cauca. Región } \\
\text { Pacífica. }\end{array}$ & Urbano. \\
\hline $\begin{array}{l}\text { 9. Crihu - Consejo } \\
\text { Regional Indígena del } \\
\text { Huila }\end{array}$ & $\begin{array}{c}9 \text { de } \\
\text { noviembre } \\
\text { de } 2011 .\end{array}$ & $\begin{array}{c}\text { Consejo Regional } \\
\text { Indígena del Huila, } \\
\text { Crihu. }\end{array}$ & $\begin{array}{c}\text { Neiva, Huila. Región } \\
\text { Andina. }\end{array}$ & Étnico (indígena). \\
\hline 10. ADCampesino & $\begin{array}{c}10 \text { de agosto } \\
\text { de } 2011 .\end{array}$ & $\begin{array}{l}\text { Asociación para } \\
\text { el Desarrollo } \\
\text { Campesino, ADC. }\end{array}$ & $\begin{array}{l}\text { Pasto, Nariño. } \\
\text { Región Pacífica. }\end{array}$ & Rural. \\
\hline
\end{tabular}

Fuente: Autora (2020). Elaboración propia. 


\section{Resultados}

\subsection{Tipos de videos publicados en cada canal según su contenido audiovisual.}

Después de analizar cada uno de los 513 videos publicados en los diez canales desde su creación hasta el 31 de diciembre de 2018 (ver Tabla 4), se establecieron 18 categorías según el contenido audiovisual, todas ellas provenientes de medios predecesores de internet como la comunicación interpersonal, la literatura oral y escrita, la prensa, el cine, la radio y la televisión.

\section{Tabla 4.}

Cantidad de videos publicados en cada canal

\begin{tabular}{|l|c|}
\hline \multicolumn{1}{|c|}{ Canales de YouTube } & $\begin{array}{c}\text { Cantidad } \\
\text { de videos } \\
\text { publicados }\end{array}$ \\
\hline Ciudadcomuna & 77 \\
\hline ADCampesino & 75 \\
\hline Red Comunicaciones Wayuu & 75 \\
\hline Fundación Cultural Ojo de Agua & 70 \\
\hline Kucha Suto Colectivo & 56 \\
\hline de Fundescodes & 46 \\
\hline SabaloIN & 44 \\
\hline indigenasaintioquia & 34 \\
\hline Crihu - Consejo Regional Indígena del Huila & 26 \\
\hline Fundación Cine a la Calle & 10 \\
\hline Total de videos publicados & 513 \\
\hline
\end{tabular}

Fuente: Autora (2020). Elaboración propia.

En la tabla 5, se pueden ver las 18 categorías que se establecieron y la cantidad de videos que se ubicaron dentro de cada una ordenados de mayor a menor. Los documentales y videos publicitarios encabezan esta tabla. 
Tabla 5.

Categorías establecidas y cantidad de videos ubicados en cada una en orden descendente

\begin{tabular}{|l|c|}
\hline $\begin{array}{c}\text { Categorías de } \\
\text { contenido audiovisual } \\
\text { establecidas }\end{array}$ & $\begin{array}{c}\text { Cantidad de } \\
\text { videos }\end{array}$ \\
\hline Documental & 235 \\
\hline Publicitario & 72 \\
\hline Ficción & 46 \\
\hline Informativo & 41 \\
\hline Institucional & 30 \\
\hline Resumen & 22 \\
\hline Musical & 17 \\
\hline De prueba & 8 \\
\hline Documento & 8 \\
\hline Docuficción & 7 \\
\hline Didáctico & 7 \\
\hline Demo & 6 \\
\hline Mensaje & 5 \\
\hline Opinión & 3 \\
\hline Presentación & 2 \\
\hline Obra de teatro & 2 \\
\hline Explicativo & 1 \\
\hline Fragmento & 1 \\
\hline
\end{tabular}

Fuente: Autora (2020). Elaboración propia.

En la tabla 6 se puede ver la cantidad de categorías de contenido audiovisual halladas en cada canal. Los de más variedad de categorías fueron Kucha Suto Colectivo y Fundación Cultural Ojo de Agua, con nueve en cada uno.

Tabla 6.

Cantidad de categorías de contenido audiovisual en cada canal

\begin{tabular}{|l|c|}
\hline \multicolumn{1}{|c|}{ Canales de YouTube } & $\begin{array}{c}\text { Categorías } \\
\text { en cada } \\
\text { canal }\end{array}$ \\
\hline Kucha Suto Colectivo & 9 \\
\hline Fundación Cultural Ojo de Agua & 9 \\
\hline ADCampesino & 8 \\
\hline Ciudadcomuna & 8 \\
\hline $\begin{array}{l}\text { Crihu - Consejo Regional } \\
\text { Indígena del Huila }\end{array}$ & 8 \\
\hline de Fundescodes & 8 \\
\hline
\end{tabular}




\begin{tabular}{|l|l|}
\hline Red Comunicaciones Wayuu & 7 \\
\hline SabaloIN & 7 \\
\hline Indigenasaintioquia & 6 \\
\hline Fundación Cine a la Calle & 5 \\
\hline
\end{tabular}

Fuente: Autora (2020). Elaboración propia.

En la tabla 7 se puede observar la cantidad y el porcentaje de canales en los que se encuentra cada una de las categorías establecidas. Los documentales y publicitarios se encuentran en los diez canales, seguidos de los resúmenes, presentes en nueve de los canales.

Tabla 7.

Cantidad y porcentaje de canales en los que se encuentran las categorías de contenido audiovisual establecidas

\begin{tabular}{|l|c|c|c|}
\hline $\begin{array}{c}\text { Categorías de } \\
\text { contenido audiovisual } \\
\text { establecidas }\end{array}$ & $\begin{array}{c}\text { Cantidad de } \\
\text { videos }\end{array}$ & $\begin{array}{c}\text { Cantidad } \\
\text { de canales en los } \\
\text { que se encuentra } \\
\text { cada categoría }\end{array}$ & Porcentaje \\
\hline Documental & 235 & 10 & $100 \%$ \\
\hline Publicitario & 72 & 10 & $100 \%$ \\
\hline Resumen & 22 & 9 & $90 \%$ \\
\hline Ficción & 46 & 6 & $60 \%$ \\
\hline Informativo & 41 & 6 & $60 \%$ \\
\hline Musical & 17 & 6 & $60 \%$ \\
\hline Institucional & 30 & 5 & $50 \%$ \\
\hline Documento & 8 & 4 & $40 \%$ \\
\hline Docuficción & 7 & 4 & $40 \%$ \\
\hline Didáctico & 7 & 3 & $30 \%$ \\
\hline Mensaje & 5 & 3 & $30 \%$ \\
\hline Demo & 6 & 2 & $20 \%$ \\
\hline Presentación & 2 & 2 & $20 \%$ \\
\hline De prueba & 8 & 1 & $10 \%$ \\
\hline Opinión & 3 & 1 & $10 \%$ \\
\hline Obra de teatro & 2 & 1 & $10 \%$ \\
\hline Explicativo & 1 & 1 & $10 \%$ \\
\hline Fragmento & 1 & 1 & $10 \%$ \\
\hline
\end{tabular}

Fuente: Autora (2020). Elaboración propia. 
A continuación se describen de forma más detallada las 18 categorías de contenido audiovisual establecidas en esta investigación.

Los documentales, definidos por el Instituto de Estadística de la Unesco (UIS, por su sigla en inglés) como "trabajos no ficticios que exponen eventos reales o intentan informar al espectador sobre alguna situación verídica" (2016, p. 24), resultaron ser el tipo de contenido más publicado en estos diez canales: se encontraron 235, el 45.81 por ciento del total, lo que marca una diferencia con los documentales comerciales o industriales que en general están en desventaja numérica frente a las producciones de ficción [4], al parecer en estos canales es muy marcado el interés por mostrar las diferentes realidades vividas en cada contexto en temas como la forma de enfrentar problemas sociales, las expresiones culturales y el cuidado del medioambiente, entre muchos otros

El canal con más documentales publicados es Ciudadcomuna, con un total de 61, la mayoría de los cuales se dedican a abordar temáticas de tipo social, con un especial énfasis en la búsqueda de soluciones a los diferentes problemas que enfrentan los habitantes de zonas vulnerables de Medellín y de algunos municipios del departamento de Antioquia, sobre todo de la Comuna 8 , zona eje del trabajo de la Corporación para la Comunicación Ciudad Comuna, sin embargo el documental más visto que se encontró fue Archivo Isla Gorgona, publicado en 2013 en el canal SabaloIN de Sábalo Producciones (Manizales, Caldas), que contaba con 31.839 visualizaciones al momento de recolectar la información.

Los videos publicitarios, que junto con las producciones documentales son las categorías que están presentes en todos canales que conformaron la muestra, se ubican en el segundo lugar respecto a su cantidad: se encontraron 72 videos de este tipo (el 14.04 por ciento).

Es importante resaltar que estos videos son en su mayoría invitaciones a participar en eventos organizados por estos grupos en sus respectivas regiones, tales como festivales de música, cine o gastronomía, o campañas de promoción de alguna causa, como puede ser el cuidado del medioambiente. Un ejemplo de estos videos es el titulado Llega el IV encuentro de Saberes y Sabores Tradicionales!!! (sic), publicado en 2017, en el canal ADCampesino.

En esta categoría se incluyeron diez tráileres o avances publicados en cuatro de los canales (Fundación Cine a la Calle, ciudadcomuna, Fundación Cultural Ojo de Agua y ADCampesino), con los que se busca que los usuarios conozcan la existencia de una producción audiovisual o teatral y puedan atribuirle "características determinadas que le ayuden a distinguirla del resto", según Dornaleteche (2002, p. 100), para quién los tráileres tienen tres características esenciales: son al mismo tiempo herramientas de comunicación publicitaria, son un tipo de publicidad específica, y constituyen un género de entretenimiento autónomo digno de contemplación y de reflexión (2002, p. 115).

De un tipo de producción audiovisual a la que se ha denominado resumen o videorresumen, se encontraron 22 videos (el 4.29 por ciento del total), en nueve de los canales. Los video resúmenes son producciones de duración breve en los que se muestran los aspectos más importantes de un suceso o evento determinado, generalmente en orden desde el inicio hasta el final (se puede decir que es una estructura clásica de inicio, intermedio y desenlace). Los dos canales que más publican este tipo de videos son ADCampesino, de la Asociación Campesina de Colombia ADC de Pasto (Nariño), con siete, y SabaloIN, perteneciente a Sábalo Producciones de Manizales (Caldas), con cuatro. 
Respecto a los videos de ficción, se encontraron en total 46 (esto es el 8.97 por ciento) en seis canales. En este tipo de producciones se representan historias imaginarias o basadas en hechos sucedidos en la realidad con la participación de actores reales o con el uso de títeres, marionetas o técnicas de animación, como puede ser la llamada cutout, hecha con recortes de papel.

En su mayoría las producciones de ficción encontradas son originales de los grupos que conformaron la muestra, sólo se encontró un video que fue la excepción, se trata de la producción estadounidense de cine mudo titulada Neighbors (1920) publicada en el canal Fundación Cultural Ojo de Agua en 2016 con el título de Vecinos de Buster Keaton con subtítulos.

Este mismo canal es el que lidera en cantidad de producciones de ficción publicadas, con un total de 27, de las que se resalta el trabajo de sus integrantes con dos grupos etarios que son al mismo tiempo diferentes y complementarios: los niños y los adultos mayores habitantes de diferentes municipios de los departamentos de Boyacá y Santander, zonas donde la fundación tiene su mayor campo de acción, como ejemplo de esto está la producción Después de la guerra (2017) creada por estudiantes y docentes de una institución educativa rural de Barichara (Santander), con base en una investigación realizada con habitantes del municipio, en la que se representa cómo construyeron la paz en un territorio que padeció la violencia bipartidista de mediados del siglo XX.

Por otra parte, se hallaron 41 videos de tipo informativo (es decir, el 7.99 por ciento del total) en seis de los canales, la mayoría de ellos en los canales Red Comunicaciones Wayuu (17) e indigenasantioquia (13), creados por integrantes de comunidades indígenas, los cuales se clasificaron en tres clases, de acuerdo con la propuesta de Cebrián Herreros (1983, citado por Mas, 2011, p. 104): referenciales, dialógicos e híbridos.

Los 29 de tipo referencial se caracterizan por tener "un arranque y una entrada o lead, un desarrollo y un cierre" (Mas, 2011, p. 104), la mayor parte de los encontrados utilizan un locutor en modo voz en off que narra las noticias mientras se muestran las imágenes de los sucesos, aunque en algunos se usan las figuras del presentador de noticias o del reportero de campo. Los tres videos de tipo dialógico son entrevistas en las que se indaga, consulta, coopera, participa o polemiza a propósito de una información (con base en Mas, 2011, p. 104); y los nueve videos de tipo híbrido incluyen características de las dos clases anteriores como se puede ver en los magacines televisivos publicados en los canales Red Comunicaciones Wayuu y Kucha Suto Coletivo.

También se encontraron 17 videos musicales (esto es un 3.31 por ciento del total) en seis de los canales de YouTube, entre videoclips, grabaciones de presentaciones en vivo y un archivo de audio editado con una imagen estática, este último se titula Gas natural para Palenque (2013) y fue publicado en el canal Kucha Suto Colectivo, del grupo del mismo nombre ubicado en el corregimiento de San Basilio de Palenque (municipio de Mahates, Bolívar), canal en el que se encontraron cuatro videos musicales, la misma cantidad que en los canales ciudadcomuna (de la Corporación para la Comunicación Ciudad Comuna de Medellín), y de Fundescodes (de la Fundación del mismo nombre, ubicada en Buenaventura, Valle del Cauca), en los que estos videos son en su mayoría videoclips de canciones pertenecientes a géneros musicales contemporáneos como el rap o el reguetón, en el caso del primer canal hay espacio tanto para estos como para para los ritmos de origen africano, por ejemplo la tradicional chalupa o el moderno soukus.

Otra categoría está conformada por los videos institucionales, que según el Ministerio de Cultura de Colombia son producciones audiovisuales que "divulgan las labores, beneficios o programas de instituciones públicas, privadas o mixtas" (2017, p. 6). De este tipo de videos se encontraron 30 , es decir, el 5.85 por ciento, en cinco de los canales, algunos de los cuales se realizaron en 
coproducción o con el patrocinio de entidades públicas como los ministerios de Cultura, del Interior, o del Ambiente y Desarrollo Sostenible, gobernaciones departamentales o secretarías locales. Los dos canales en los que más se publicaron videos de este tipo son de Fundescodes (11) y Kucha Suto Colectivo (9).

De un tipo de producción audiovisual a la que se ha llamado documento o videodocumento se encontraron ocho producciones (esto es el 1.56 por ciento) en cuatro de los canales. Se puede decir que un videodocumento es un registro audiovisual de un momento de la vida real, una especie de fotografía en movimiento que en general se realiza con una sola cámara y una sola toma y no tiene un gran trabajo de edición. Los canales en los que más se encontraron este tipo de registros de la realidad son de Fundescodes y Crihu - Consejo Regional Indígena del Huila, con tres en cada uno.

Uno de los hallazgos más interesantes de esta categoría de la investigación lo constituyen los videos que se clasificaron como de docuficción, híbridos entre documental y ficción, diferentes de los llamados falsos documentales, que pueden considerarse parte del mundo de la ficción. En una docuficción se puede encontrar algo como un personaje ficticio entrevistando a personas reales o viceversa. El origen de este tipo de producciones se encuentra en la literatura, donde autores como Martínez (2014) lo conceptualizan como una combinación ambigua de elementos, técnicas y estrategias de la realidad y de la ficción. Esta "ambigüedad presenta una estrategia narrativa referencial y ficcional al mismo tiempo, no de forma intermitente y fragmentada, sino de forma simbiótica e integral" (Martínez, 2014, p. 29). De estos experimentos narrativos audiovisuales se encontraron siete, es decir, el $1.36 \%$ del total, en cuatro de los canales. El canal que más ha incursionado en este tipo de producciones es Fundación Cultural Ojo de Agua con tres, una de las cuales, a modo de ejemplo, es El misterioso caso de las ceibas (2015).

La siguiente categoría establecida es la de los videos didácticos, que según Marquès Graells (1999) son aquellos que "son elaborados con una intencionalidad específica educativa" y entre los cuales se encuentran los videos tutoriales, en los que se explican de forma detallada y simple los pasos para realizar algo. De estos videos se encontraron en total siete (el 1.36 por ciento) en tres de los canales. La gran mayoría (cinco) se encontraron en el canal ADCampesino, estos están enfocados en enseñar temas de la vida rural, como se puede ver en el video titulado Consejos para una buena huerta casera (2018).

En tres de los canales se encontraron cinco videos (el 0.97 por ciento) que conforman la categoría denominada mensajes o videomensajes, que tienen su origen en las cartas, postales y tarjetas, en los que se envían saludos, felicitaciones por una fecha o suceso especial, y solicitudes a destinatarios específicos ya sean individuales o grupales.

El canal en el que más se encontraron este tipo de videos fue ADCampesino, con tres. A modo de ejemplo dos videomensajes muy diferentes son: 8 de marzo - Homenaje a la mujer rural (2018), una tarjeta en video publicada en el canal ADCampesino, y Arroyo Bruno - \#EIAguaEsNuestra Solicitud a gobernadora Oneida (2016), publicado en el canal Red Comunicaciones Wayuu, dirigido a la gobernadora de La Guajira de ese entonces para pedirle que cumpliera sus promesas de campaña respecto al cuidado de los recursos hídricos de este departamento, afectados durante más de tres décadas por la explotación minera por parte de la multinacional Carbones del Cerrejón Limited, y que no permitiera el desvío del arroyo Bruno porque dejaría sin agua a muchos habitantes.

La categoría a la que se llamó demo está conformada por seis videos (es decir, el 1.17 por ciento del total) publicados en dos de los canales: Fundación Cultural Ojo de Agua (seis), y Kucha Suto Colectivo (uno). En estos videos se publican muestras breves del trabajo realizado por una persona 
o grupo para darse a conocer con diferentes fines: publicitarios, laborales, entre otros. Un video de este tipo también se puede llamar videoportafolio o reel.

Dos videos (el 0.39 por ciento), encontrados en los canales de Fundescodes y Crihu - Consejo Regional Indígena del Huila, conforman la categoría llamada presentación o presentación de diapositivas. En estos se exponen datos sobre diversos temas haciendo uso de elementos como fotografías, animaciones, música, efectos de sonido o videos, se pueden realizar con programas como Power Point de Microsoft y se guardan en formatos de video tales como MP4 o WMV para ser publicados en YouTube. Los dos videos encontrados son Lo que soy yo (2013), con fotografías que muestran las diferentes actividades (recreativas, artísticas y educativas) realizadas por los niños y jóvenes vinculados a Fundescodes en Buenaventura, y Octava promoción de la institución educativa Yu Luucx Pishaw (2013) que contiene imágenes de la graduación de los estudiantes de un colegio ubicado en el Resguardo Nasa de Juan Tama (Huila).

Las últimas cinco categorías se hallaron en un canal cada una. La primera de estas se denominó videos de prueba, y se encontraron ocho de estos (el 1.56 por ciento del total) en el canal Red Comunicaciones Wayuu. En estas publicaciones se demuestran conocimientos, intereses o talentos de forma individual o grupal con la intención de llegar a ser elegido para participar en algún tipo de actividad, sea laboral, académica o artística, por lo que también se les puede llamar videos de casting, de selección o de audición. En el caso de los videos encontrados se puede decir que tienen una finalidad académica ya que quienes los realizaron son jóvenes de la etnia Wayuu interesados en hacer parte de la Escuela de Comunicaciones del Pueblo Wayuu - Pütchiimaajana en el año 2016.

Tres videos (esto es el 0.58 por ciento del total) publicados en el canal indigenasantioquia de la Organización Indígena de Antioquia (OIA) en 2017 conforman la categoría llamada videos de opinión. En estos se expresan y se argumentan puntos de vista sobre asuntos determinados, que por lo general tienen que ver con hechos noticiosos de carácter local, regional o nacional: el desarme de las Farc y la liberación de un líder indígena que estaba en prisión, en el caso de estos tres videos. Como no se encontraron más videos de este tipo dentro de las publicaciones del canal no se pueden clasificar como parte del videocolumnismo al que se refieren Gaviria y Polo (2019), para el que se requiere que los videos con contenido de opinión se publiquen de forma periódica (cada semana, cada quincena, cada mes), tal como sucede con los columnistas de los medios escritos tradicionales.

Por otra parte, dos videos (es decir, el 0.39 por ciento) publicados en el canal Fundación Cultural Ojo de Agua en 2015, conforman la categoría llamada obras de teatro. Estos videos son más que una obra teatral grabada (esto lo acercaría más a lo que en este artículo se ha definido como documento o videodocumento), son en realidad versiones en video de las obras teatrales realizadas de forma profesional cuidando detalles artísticos y técnicos, y editadas de forma que quien las vea viva la experiencia como si en realidad estuviera en la sala de teatro, como lo hace por ejemplo el National Theatre del Reino Unido con el proyecto National Theatre Live, que desde el año 2009 lleva obras de teatro en vivo o grabadas a salas de cine alrededor del mundo. Las dos obras publicadas son las producciones del Teatro Itinerante del Sol de Villa de Leyva (Boyacá) Omaira (2015) y Orígenes hacia el sur (2015).

Las dos últimas categorías corresponden a dos videos publicados en el canal ciudadcomuna: Desalojo en 5 pasos (publicado en 2015) es un video explicativo, y Jairo Maya innovador de la memoria (publicado en 2016) es un fragmento. El primero corresponde a un tipo de video animado que surgió en el mundo de la publicidad y que busca explicar ideas de forma sencilla y entretenida, 
y cuyo uso se ha expandido a diferentes campos, entre ellos el activismo digital o ciberactivismo, como sucede en el caso particular del video mencionado: es producido por las ONG Witness y Amnistía Internacional con la finalidad de concienciar sobre el problema de los desalojos por diferentes causas (por ejemplo, por proyectos de renovación urbana) a comunidades vulnerables ubicadas en distintos lugares del mundo.

El segundo video hace parte de un capítulo del programa de televisión Voces que suman, emitido originalmente por el canal regional Teleantioquia en el año 2015, y contiene un reportaje sobre un líder social muy apreciado en su comunidad, la comuna 8 de Medellín.

La información sobre la cantidad y porcentaje de videos publicados en cada una de las categorías establecidas en esta investigación se encuentra detallada en la Figura 1.

Figura 1.

Categorías de videos establecidas

\begin{tabular}{|c|c|c|c|c|c|c|c|c|c|c|c|c|}
\hline 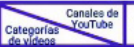 & 1 & 2 & 3 & 4 & 5 & 6 & 7 & 8 & 9 & 10 & Total & \begin{tabular}{|l|} 
Porcentaje \\
\end{tabular} \\
\hline Documental & 27 & 5 & 26 & 61 & 12 ? & 27| & 22 & 14 & 7 & 34 & 235 & $45.81 \%$ \\
\hline Publicitario & 5 & 1 & 21 & 5 & 4 & 8 & 7 & 7 & 2 & 12 & 72 & $14.04 \%$ \\
\hline Resumen & 3 & 1 & 1 & 2 & 1 & 4 & & 2 & 1 & 7 & 22 & $4.29 \%$ \\
\hline Ficclón & 2 & 2 & & & & & 27 & 4 & 4 & 7 & 46 & $8.97 \%$ \\
\hline Informativo & 4 & & 17 & 1 & 13 & 1 & & & 5 & & 41 & $7.99 \%$ \\
\hline Musical & 4 & & 1 & 4 & & & 1 & 4 & 3 & & 17 & $3.31 \%$ \\
\hline Institucional & 9 & & & 2 & & & 2 & 11 & & 6 & 30 & $5.85 \%$ \\
\hline Documento & & & & & & 1 & & 3 & 3 & 1 & 8 & $1.56 \%$ \\
\hline Docuficción & 1 & 1 & & & & 2 & 3 & & & & 7 & $1.36 \%$ \\
\hline Didáctioo & & & & & 1 & & 1 & & & 5 & 7 & $1.36 \%$ \\
\hline Menssje & & & 1 & & & 1 & & & & 3 & 5 & $0.97 \%$ \\
\hline Demo & 1 & & & & & & 5 & & & & 6 & $1.17 \%$ \\
\hline Presentación & & & & & & & & 1 & 1 & & 2 & $0.39 \%$ \\
\hline De prueba & & & 8 & & & & & & & & 8 & $1.56 \%$ \\
\hline opinión & & & & & 3 & & & & & & 3 & $0.58 \%$ \\
\hline \begin{tabular}{|l} 
obra de teatro \\
\end{tabular} & & & & & & & 2 & & & & 2 & $0.39 \%$ \\
\hline Explicativo & & & & 1 & & & & & & & 1 & $0.19 \%$ \\
\hline Fragmento & & & & 1 & & & & & & & 1 & $0.19 \%$ \\
\hline
\end{tabular}

Fuente: Autora (2020). Elaboración propia.

\subsection{Clases de videos según su duración.}

La mayoría de los 513 videos publicados en los diez canales pertenecen a dos de las categorías establecidas: 321, es decir, el 62.57 por ciento, son minimetrajes (la mayor parte de los videos publicados en seis de los canales: Kucha-Suto Colectivo, Red Comunicaciones Wayuu, indigenasantioquia, SabaloIN, de Fundescodes y Crihu - Consejo Regional Indígena del Huila, como se evidencia en la figura 2), y 185, esto es el 36.06 por ciento, son cortometrajes (la mayoría de las publicaciones de los canales Fundación Cine a la Calle, ciudadcomuna, Fundación Cultural Ojo de Agua y ADCampesino). Estas dos categorías están presentes en los diez canales. Por otra parte, sólo cuatro de los videos publicados (el 0.78 por ciento) en tres canales (Red Comunicaciones Wayuu, CRIHU - Consejo Regional Indígena del Huila y ADCampesino) son micrometrajes, y tres 
(el 0.58 por ciento) publicados en dos canales (Ciudadcomuna y Fundación Cultural Ojo de Agua) son largometrajes.

\section{Figura 2.}

Cantidad de videos según duración publicados en cada canal

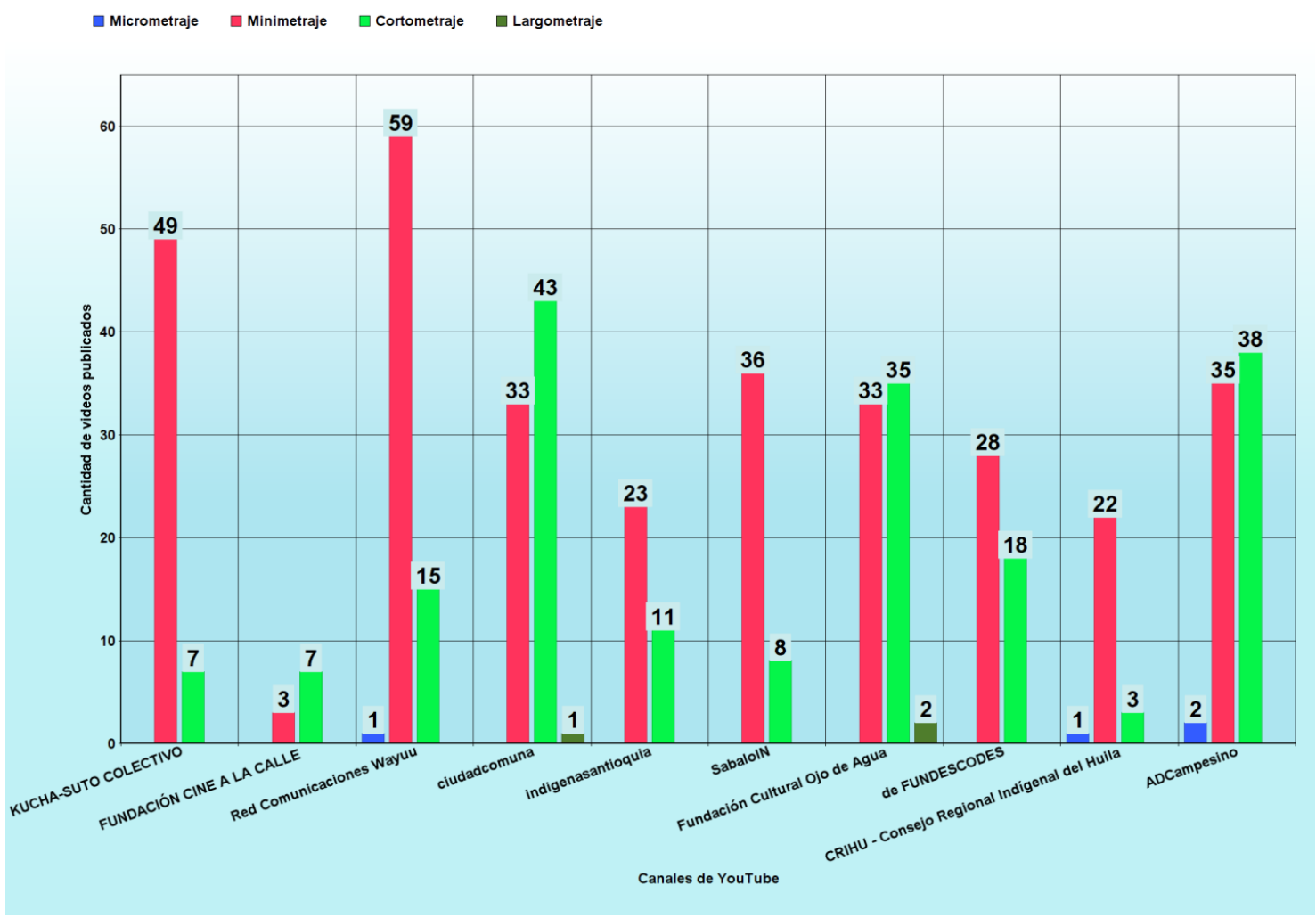

Fuente: Autora (2020). Elaboración propia.

La preferencia por publicar videos de duración breve coincide tanto con el tiempo de permanencia de los usuarios de YouTube a nivel mundial, que en 2018 fue en promedio de 8 minutos y 41 segundos diarios (según cifras de Alexa.com, 2018, citadas por Newberry y Adame, 2019), como con las preferencias de los usuarios de estos diez canales, como se evidencia al revisar la duración de los videos más vistos de cada uno: son minimetrajes y cortometrajes en partes iguales (50\%), como se puede ver en el siguiente cuadro comparativo. 
Figura 3.

Videos más vistos en los diez canales.

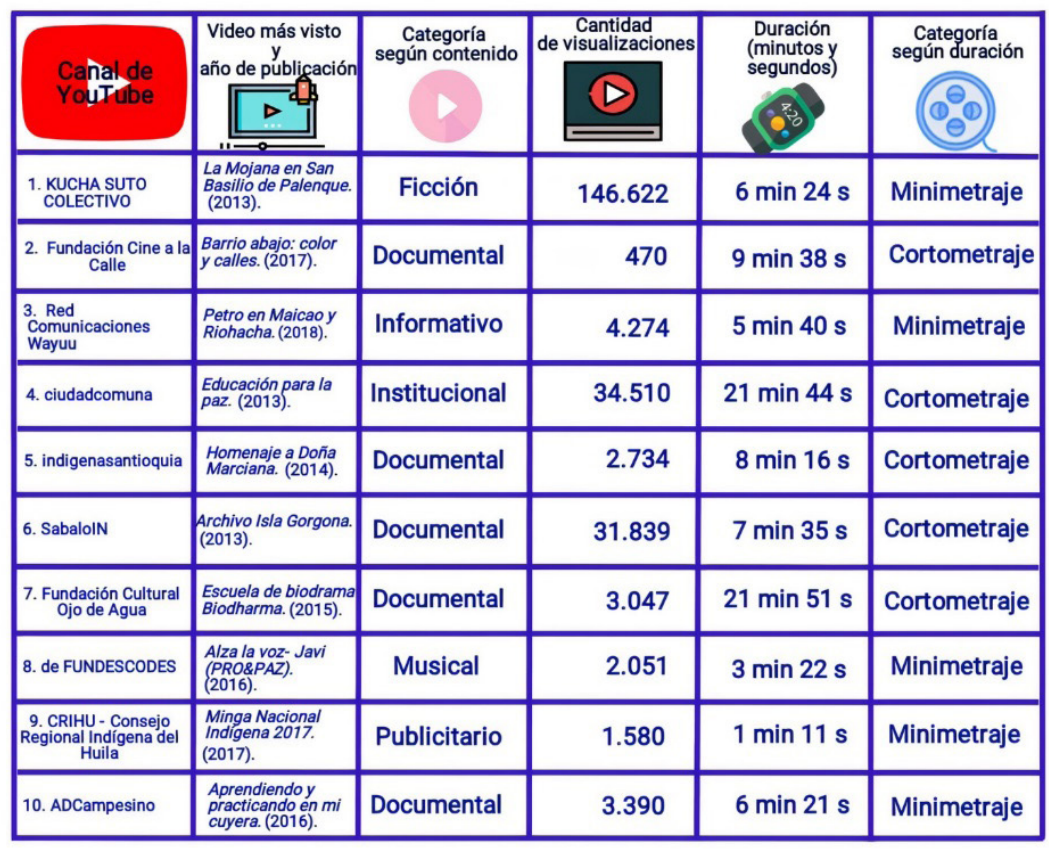

Fuente: Autora (2020). Elaboración propia.

\section{Conclusiones}

En síntesis, en los diez canales de YouTube que conformaron la muestra se publicaron, desde la creación de cada uno y hasta el 31 de diciembre de 2018, 513 videos que se clasificaron en 18 categorías: documentales, publicitarios, resúmenes o videorresúmenes, de ficción, informativos, musicales, institucionales, documentos o videodocumentos, docuficciones, didácticos, mensajes o videomensajes, demos, presentaciones, de prueba, de opinión, obras de teatro, explicativos y fragmentos. Los videos que se publican en mayor cantidad son los documentales, seguidos por los publicitarios, los de ficción, los informativos, institucionales, resúmenes y musicales. Las dos primeras categorías están presentes en el 100 por ciento de los canales que hicieron parte de la investigación. Por otra parte, aunque se encontraron videos pertenecientes a las cuatro categorías de duración establecidas, la mayoría son minimetrajes y cortometrajes.

Las 18 categorías de publicaciones establecidas, en una muestra de apenas diez canales de YouTube abiertos y utilizados por grupos colombianos dedicados a la producción audiovisual comunitaria o participativa, demuestran que esta plataforma digital facilita a estos grupos publicar una amplia variedad de contenidos audiovisuales de manera permanente, lo cual resulta favorable frente a los espacios habituales de exhibición de estas producciones, como los festivales de audiovisual comunitario, que por lo general duran unos pocos días y tienen una cantidad limitada de categorías de participación (generalmente siempre están las categorías de documental y ficción, y dependiendo del festival se incluyen unas pocas categorías más como pueden ser animación o video experimental). 
Dentro de esta gran variedad de contenidos publicados, es evidente el interés de estos grupos comunitarios o participativos por mostrar sus producciones propias o en las que tienen alguna participación (por ejemplo como coproductores o realizadas con el apoyo de alguna entidad pública), pues de los 513 videos observados en los diez canales apenas unos pocos corresponden a producciones realizadas en su totalidad por otros y compartidos en tres de estos (Kucha Suto Coletivo, ciudadcomuna y Fundación Cultural Ojo de Agua).

Respecto a la preferencia por publicar videos de duración breve en los diez canales, es afín con la tendencia de los usuarios a preferir este tipo de videos, no sólo de los usuarios que ven los canales que hicieron parte de la investigación, sino de la plataforma YouTube tanto en el ámbito global como en el colombiano, lo que se puede comprobar al ver los promedios de permanencia diaria de los usuarios en la plataforma, o revisando los listados de videos más vistos cada año [5], por lo que resulta recomendable que en estos canales se sigan publicando más videos de duración breve, ya que tienen mayores probabilidades de ser vistos por una cantidad mayor de público.

Aunque al momento de escribir este artículo se piense en general en YouTube como un medio lucrativo más que en un medio participativo, se hable de los llamados youtubers como de celebridades ciberespaciales que logran en algunos cuantos casos ganar miles de dólares por factores como la popularidad de sus publicaciones y el interés de los anunciantes en ellas, y hasta se haya creado una versión de pago de la plataforma (YouTube Premium), al estilo de Netflix, en la que los usuarios se suscriben para acceder a contenidos producidos de forma profesional (series, películas, documentales, videos musicales, entre otros) libres de publicidad, es importante que se mantenga en el largo plazo la posibilidad de uso gratuito que favorece a grupos como los que crearon los canales que conformaron la muestra del estudio referenciado, que tienen intereses diferentes a la obtención de beneficios económicos o de fama, que merecen seguir teniendo acceso a una pequeña parte del inmenso ciberespacio que les permite tener presencia más allá del espacio físico de sus propias comunidades.

En ese sentido, se espera que este artículo contribuya a que más usuarios de YouTube se interesen en las producciones audiovisuales publicadas en estos diez canales, ya que es una forma de acceder, desde la pantalla de cualquier dispositivo tecnológico conectado a internet, a diferentes comunidades que hacen parte de Colombia, y conocer aspectos tan diversos como sus riquezas culturales, sus valores y saberes ancestrales, su historia, su interés por la preservación del medioambiente, sus problemas sociales o las soluciones que en diferentes casos han logrado darles a éstos, los cuales quedaron evidenciados en la segunda parte de esta extensa investigación con el análisis de los 235 documentales hallados, cuyos resultados la autora espera poder publicar en un próximo artículo.

Por último, es deseable que estos resultados les sean de utilidad a los integrantes de los diez grupos cuyos canales de YouTube hicieron parte de esta investigación para conocer los distintos tipos de contenido audiovisual que se producen en otros de su tipo, quizá esto los motive a incursionar en la producción de videos de categorías halladas en pocos canales, como los de opinión (que de hacerse de forma periódica se consideran videocolumnas), los didácticos, o los de docuficción; para saber cuáles categorías de videos según su duración son las preferidas de los usuarios, y así producir y publicar más producciones audiovisuales que pertenezcan a esas categorías; y para que ante la gran variedad de contenidos que producen estos grupos y publican en sus canales, los organizadores de los diferentes festivales de audiovisual comunitario o participativo que se realicen en Colombia, sea de forma presencial o virtual (teniendo en cuenta las circunstancias derivadas de la pandemia del covid-19) creen nuevas categorías de participación, por ejemplo, la de video publicitario o la de video informativo. 


\section{Referencias}

Aguilera, C., y Polanco, G. (2011). Video comunitario, alternativo, popular... Apuntes para el desarrollo de políticas públicas audiovisuales. Santiago de Cali: Programa Editorial Universidad del Valle. Disponible en: http://videocomunidad.univalle.edu.co/descargas/Libro Video_Comunitario_Alternativo_Popular.pdf

Aizpuru, M. (2016). El audiovisual como herramienta de cambio social de jóvenes en situación de exclusión en Guatemala (2004-2014) (Tesis doctoral). Universidad Complutense de Madrid: Madrid, España. Disponible en: http://eprints.ucm.es/38152/1/T37397.pdf

Álvarez, S. (2013). La producción audiovisual hecha por jóvenes como herramienta para el reconocimiento comunitario y la construcción de ciudadanía: la experiencia del proyecto «mi mirada, nuestra mirada» en Salta, Argentina. En I. A. (Coord.), Investigar con jóvenes: ¿qué sabemos de los jóvenes como productores de cultura visual? (pp. 204-211). Pamplona: Grupo de Investigación Edarte. Disponible en: https:// academica-e.unavarra.es/bitstream/handle/2454/19798/ProduccionAudiovisual. pdf? sequence $=1$ \&isAllowed $=\mathrm{y}$

Amador, A. (2017). El cine comunitario: un medio de expresión y creación de memoria colectiva en Aguascalientes. Estudio de tres casos (Tesis de maestría). Universidad Autónoma de Aguascalientes: Aguascalientes, México. Disponible en: http://bdigital.dgse.uaa. mx:8080/xmlui/bitstream/handle/11317/1364/419271.pdf? sequence=1\&isAllowed=y

Arjona, J. (2012). Estudio cuantitativo de la televisión y el video por web (webcasting o webtv): análisis de la unidireccionalidad e interactividad. Área Abierta, 31(1), 1-34. Disponible en: https://revistas.ucm.es/index.php/ARAB/article/view/38970/37602

Andréu, J. (2001). Las técnicas de Análisis de Contenido: una revisión actualizada. Fundación Centro Estudios Andaluces, Universidad de Granada 10(2), 1-34.

Brisset, D. (2015). Nueva tipología de los productos audiovisuales (según su duración). Málaga: Universidad de Málaga. Disponible en: https://riuma.uma.es/xmlui/bitstream/ handle/10630/10237/Nueva\%20tipolog\%C3\%ADa\%20de\%20productos\%20 audiovisuales $\% 20-\% 20 \mathrm{D} . \% 20 \mathrm{E} . \% 20 \mathrm{Brisset}$.pdf?sequence=1\&isAllowed=y

Castells, M. (2008). Comunicación, poder y contrapoder en la sociedad red (I). Los medios y la política. Telos 74, 13-24.

Castells, M. (2009). Comunicación y poder. Traducción de María Hernández. Madrid: Alianza Editorial.

Cloutier, J. (1973). La communication audio-scripto-visuelle à l'heure des self média. Montreal: Les Presses de l'Université de Montreal.

Cloutier, J. (2001). Petit traité de communication. Emerec à I'heure des technologies numériques. Montreal: Carte Blanche.

Cuevas, J. (2016). Experiencia de video participativo con un grupo de jóvenes sordos como alternativa a la discriminación lingüística que enfrentan (Tesis de maestría). Universidad Iberoamericana Puebla: Puebla, México. Disponible en: https://repositorio. iberopuebla.mx/bitstream/handle/20.500.11777/2515/Cuevas\%20Parra\%20Julieta. pdf? sequence $=1$ \&isAllowed $=y$

Dornaleteche, J. (2007). Definición y naturaleza del tráiler cinematográfico. Pensar la publicidad. Revista Internacional De Investigaciones Publicitarias, 1(2), 99-116. Disponible en: https://revistas.ucm.es/index.php/PEPU/article/view/PEPU0707220099A/15662 
Fernández, S. (2015). Periodismo en YouTube: análisis de contenido en los canales de Atresmedia y RTVE (Tesis de pregrado). Universidad de Valladolid: Valladolid, España. Disponible en: $\quad$ https://uvadoc.uva.es/bitstream/handle/10324/17585/TFG F_2015_129. pdf? sequence $=1 \&$ isAllowed $=y$

Garcés, A. (2015). Colectivos juveniles en Medellín. Configuración de las subjetividades juveniles vinculadas a la comunicación audiovisual participativa y comunitaria (Tesis doctoral). Universidad Nacional de La Plata: La Plata, Argentina. Disponible en: $\quad$ http://sedici.unlp.edu.ar/bitstream/handle/10915/49916/Documento completo. pdf? sequence $=3 \&$ isAllowed $=y$

Gaviria, C., y Polo, D. (2019). Videocolumnismo. Desafíos para el periodismo de opinión. Revista Luciérnaga Comunicación. 11(21), 105-124. Disponible en: https://revistas.elpoli.edu. co/index.php/luc/article/view/Art.5/1364

Gonzales, J. (2017). Cine comunitario y prácticas andinas:el calendario festivo en la escuela Chaupin,Carhuaz-Perú (Tesis de maestría). Facultad Latinoamericana de Ciencias Sociales Sede Ecuador: Quito, Ecuador. https://repositorio.flacsoandes.edu.ec/xmlui/ bitstream/handle/10469/11872/TFLACSO-2017JCGO.pdf?sequence=2\&isAllowed=y

Gumucio, A. (2014). El cine comunitario en América Latina y el Caribe. Bogotá D.C.: FriedrichEbert-Stiftung FES (Fundación Friedrich Ebert). Disponible en: https://library.fes.de/ pdf-files/bueros/la-comunicacion/10917.pdf

Hernández, R., Fernández, C., y Baptista, P. (2010). Metodología de la investigación. Quinta edición. México D.F., México: McGrawHill.

Hernández, R., Fernández, C., y Baptista, P. (2014). Metodología de la investigación. Sexta edición. México D.F., México: McGrawHill.

Iriarte, P., y Miranda, W. (2011). Los usos del audiovisual en el Caribe colombiano: relato desde las organizaciones, los realizadores y los colectivos. Bogotá D.C.: Observatorio del Caribe Colombiano, Ministerio de Cultura.

Lopera, J. (2019). Prácticas, saberes y apropiación del medio audiovisual en los colectivos de comunicación comunitaria de la ciudad de Medellín. Revista Luciérnaga Comunicación, 11(22), 70-83. Disponible en: https://doi.org/10.33571/revistaluciernaga.v11n22a2

Mcluhan, M. (1996). Comprender los medios de comunicación. Las extensiones del ser humano. Barcelona: Paidós.

Marquès, P. (1999). Los videos educativos. Barcelona, España: http://www.peremarques.net/ Disponible en: http://www.peremarques.net/videoori.htm

Martínez, J. (2014). Autoficción y docuficción como propuestas de sentido. Razones culturales para la representación ambigua. Castilla. Estudios de Literatura 5, 26-38. Disponible en: https://revistas.uva.es/index.php/castilla/article/view/213/214

Mas, L. (2011). Modelo superestructural de la noticia en televisión. Estudios sobre el mensaje periodístico 17(1), 95-116. Disponible en: https://revistas.ucm.es/index.php/ESMP/ article/view/36948/35757

Mazo, C. (2012). Posibilidades del audiovisual comunitario en la cibercultura (Tesis de maestría). Universidad Pontificia Bolivariana: Medellín, Colombia.

Ministerio de Cultura. (2015). Normas del cine en Colombia. Bogotá: Ministerio de Cultura. Disponible en: $\quad$ https://www.mincultura.gov.co/areas/cinematografia/Legislacion/Documents/ 


\section{Cartilla\%20-\%20Normas\%20del\%20Cine\%20en\%20Colombia.pdf}

Ministerio de Cultura. (2017). Decreto 554 de 2017. Bogotá. Disponible en: https://www.mincultura. gov.co/areas/cinematografia/Legislacion/Documents/Decreto\%20554\%20de\%20 2017.pdf

Molfetta, A. (2017). Precariado, Ley de Medios y Tercer Cine: el cine comunitario del Gran Buenos Aires y los abuelos de Berazategui. Culturas 11 Edición Especial, 49-71. Disponible en: $\quad$ https://ri.conicet.gov.ar/bitstream/handle/11336/77342/CONICET Digital Nro. ec3b29b0-7a21-4951-aa0f-786340b02625 A.pdf? sequence=5\&isAllowed=y

Newberry, C. y Adame, A. (2019). 22 estadísticas esenciales de YouTube para este año. Vancouver, Canadá: https://blog.hootsuite.com/es/ Disponible en: https://blog.hootsuite.com/es/ estadisticas-de-youtube/\#uso.

Navarro, G. (2020). Tejiendo memoria social en el ciberespacio. Documental audiovisual comunitario o participativo colombiano en YouTube. (Tesis doctoral). Universidad Nacional de Colombia: Medellín, Colombia.

ONU. (1948). La Declaración Universal de Derechos Humanos. Disponible en: http://www.un.org/ es/universal-declaration-human-rights/

Quintar, A., González, L., y Barnes, C. (2014). Producción audiovisual comunitaria: una democratización del relato. Questión 42, 360-375. https://perio.unlp.edu.ar/ojs/index.php/ question/article/view/2147/1917

Rodríguez, F. (2013). Apropiación social de las tecnologías de la información y la comunicación (TIC) en las prácticas de los colectivos de video comunitario en Colombia (Tesis de maestría). Universidad Pontificia Bolivariana: Medellín, Colombia.

Román, M. (2009). Video Comuna: política desde el audiovisual alternativo y comunitario (Tesis de maestría). Pontificia Universidad Javeriana: Bogotá, Colombia. Disponible en: $\quad$ https://repository.javeriana.edu.co/bitstream/handle/10554/235/comu2. pdf? sequence $=1$ \&isAllowed $=\mathrm{y}$

Soler, C. (2017). Media-médium: entre la etnografía y el cine comunitario. Universitas. Revista de ciencias sociales y humanas XV(27), 179-194. Disponible en: https://www.redalyc.org/ articulo.oa?id=476152665009

Torres, S. (2013). Na lavill'llaGa'c qataq nalquii na qarhuo: Apuntes sobre una experiencia de video participativo con jóvenes indígenas toba en Formosa, Argentina. Revista Chilena de Antropología Visual 22, 69-90. Disponible en. http://www.rchav.cl/2013_22_art03 torres.html

Unesco-UIS. (2016). Diversidad e industria cinematográfica. Análisis de la encuesta de la UIS del año 2014 sobre las estadísticas de largometrajes. Montréal: Unesco-UIS. Disponible en: https://unesdoc.unesco.org/ark:/48223/pf0000244829

Urrea, A. (2013). Proyectando y realizando la ciudad desde lo político (Tesis de maestría). Facultad Latinoamericana de Ciencias Sociales Sede Ecuador: Quito, Ecuador. Disponible en: $\quad$ https://repositorio.flacsoandes.edu.ec/bitstream/10469/7430/2/TFLACSO2013AMUV.pdf

Villalobos, D. (2016). YouTube como herramienta de comunicación de los canales de los medios públicos europeos: BBC, France Télévisions y RTVE (Tesis de pregrado). Universidad de Valladolid: Valladolid, España. Disponible en: https://uvadoc.uva.es/bitstream/ handle/10324/22438/TFG F 2016 177.pdf? sequence=1\&isAllowed=y 
Zabala, M. (2018). Análisis de vídeos destinados a la enseñanza del español como lengua extranjera en YouTube (Tesis de máster).Centro Universitario CIECE Fundación Comillas y Universidad de Cantabria: Comillas, España. Disponible en: http:// repositorio.unican.es:8080/xmlui/bitstream/handle/10902/16026/TFM.MZZ. pdf? sequence=1\&isAllowed=y

Zamorano, G. (2009). Intervenir en la realidad: usos políticos del video indígena en Bolivia. Revista Colombiana de Antropología 45(2), 259-285. Disponible en: https://revistas.icanh.gov. co/index.php/rca/article/view/1001/752

\section{Canales de Youtube}

Asociación para el Desarrollo Campesino, ADC. (2011-2018). Canal ADCampesino. Disponible en: https://www.youtube.com/channel/UCQbrtxVnKKF4Hu48-IvDCzw

Colectivo de Comunicaciones Kuchá-Suto de Palenque. (2012-2018). Canal KUCHA SUTO COLECTIVO. Disponible en: https://www.youtube.com/channel/UC9VUYHoWmDnV8SpN2oYgJA

Consejo Regional Indígena del Huila, Crihu. (2011-2018). Canal CHIHU - Consejo Regional Indígena del Huila. Disponible en: https://www.youtube.com/channel/UCZsUQYvFbmszZzpZvbmy6g

Corporación para la comunicación Ciudad Comuna. (2011-2018). Canal ciudadcomuna. Disponible en: https://www.youtube.com/user/ciudadcomuna

Fundación Cine a la Calle. (2017-2018). Canal Fundación Cine a la Calle. https://www.youtube.com/ channel/UCiL1zKqWUlv4_z-n79bd1nA

Fundación Cultural Ojo de Agua. (2011-2018). Canal Fundación Cultural Ojo de Agua. Disponible en: https://www.youtube.com/channel/UCTEnhfO5Rq0oaHF954xm0ow

Fundación Espacios de Convivencia y Desarrollo Social, Fundescodes. (2013-2018). Canal de FUNDESCODES. Disponible en: https://www.youtube.com/channel/ UCTpKYywTuSZSZdFObc 039A

Organización Indígena de Antioquia, OIA. (2012-2018). Canal indigenasantioquia. Disponible en: https://www.youtube.com/channel/UCWi9wLKdjEeUodkzUqhNUVg

Red de Comunicaciones del Pueblo Wayuu - Pütchiimaajana. (2015-2018). Canal Red Comunicaciones Wayuu. Disponible en: https://www.youtube.com/channel/UCeDe4 ICQF5_yAbPN435qRg

Sábalo Producciones. (2012-2018). Canal SabalolN. Disponible en: https://www.youtube.com/ channel/UCbbtHZdso MvQ-RIXnUjPw 


\section{Notas}

[1] Tesis del Doctorado en Ciencias Humanas y Sociales de la Universidad Nacional de Colombia Sede Medellín, titulada Tejiendo memoria en el ciberespacio. Documental audiovisual comunitario o participativo colombiano en YouTube.

[2] Todos los nombres de los canales de YouTube aparecen a lo largo del artículo con la escritura que determinaron sus creadores. Por eso algunos aparecen con mayúsculas sostenidas, o una parte en mayúscula y otra en minúscula; minúscula inicial, sin tildes, o palabras unidas.

[3] En el año 2020 el canal de FUNDESCODES, cambió su nombre por el de casa SOCIALCULTURALYMEMORIA. La autora consideró pertinente utilizar en este artículo el nombre que tenía el canal cuando se recolectó la información, en el año 2018.

[4] Desventaja que se evidencia en la cantidad de producciones documentales que se realizan cada año frente a las de ficción, basta revisar el banco de datos disponible en Proimágenes Colombia para comprobarlo: entre 2018 y 2019 se estrenaron en el ámbito nacional 14 documentales y 70 películas de ficción.

[5] Estos listados se publican de forma anual y están disponibles en https://www.youtube.com/user/ theyearinreviewCO.

\section{Para citar este artículo:}

Navarro, G. (2020). Video comunitario colombiano en Youtube. Tipos de contenido y duración. Revista Luciérnaga Comunicación. Vol. 12, Núm. 23. Pp 104-129. https://doi.org/10.33571/revistaluciernaga.v12n23a5

OJS. http://revistas.elpoli.edu.co/index.php/luc/issue/archive

Link. https://www.politecnicojic.edu.co/index.php/revista-luciernaga 